\title{
Disruption of endothelial adherens junctions by high glucose is mediated by protein kinase C- $\beta$-dependent vascular endothelial cadherin tyrosine phosphorylation
}

\author{
Mehran Haidari ${ }^{1,2 *}$, Wei Zhang ${ }^{2}$, James T Willerson ${ }^{1,2}$ and Richard AF Dixon ${ }^{2}$
}

\begin{abstract}
Background: Hyperglycemia has been recognized as a primary factor in endothelial barrier dysfunction and in the development of micro- and macrovascular diseases associated with diabetes, but the underlying biochemical mechanisms remain elusive. Tyrosine phosphorylation of vascular endothelial cadherin (VE-cad) leads to the disruption of endothelial adherens junctions and increases the transendothelial migration (TEM) of leukocytes.

Methods: VE-cad tyrosine phosphorylation, adherens junction integrity and TEM of monocytes in human umbilical vein endothelial cells (HUVECs) treated with high-concentration glucose were evaluated. The role of protein kinase C (PKC) in induction of endothelial cells adherence junction disruption by exposure of HUVECs to high concentration of glucose was explored.
\end{abstract}

Results: The treatment of HUVEC with high-concentration glucose increased VE-cad tyrosine phosphorylation, whereas mannitol or 3-O-methyl-D-glucose had no effect. In addition, high-concentration glucose increased the dissociation of the VE-cad- $\beta$-catenin complex, activation of the Wnt/ $\beta$-catenin pathway, and the TEM of monocytes. These alterations were accompanied by the activation of endothelial PKC and increased phosphorylation of ERK and myosin light chain (MLC). High-concentration glucose-induced tyrosine phosphorylation of VE-cad was attenuated by: 1- the inhibition of PKC- $\beta$ by overexpression of dominant-negative PKC- $\beta$ 2- inhibition of MLC phosphorylation by overexpression of a nonphosphorylatable dominant-negative form of MLC, 3- the inhibition of actin polymerization by cytochalasin $\mathrm{D}$ and 4 - the treatment of HUVECs with forskolin (an activator of adenylate cyclase).

Conclusions: Our findings show that the high-concentration glucose-induced disruption of endothelial adherens junctions is mediated by tyrosine phosphorylation of VE-cad through PKC- $\beta$ and MLC phosphorylation.

Keywords: Adherens junction, Endothelium, Wnt pathway, Protein kinase C (PKC), Diabetes

\section{Introduction}

Atherogenesis is a vascular inflammatory process characterized by the enhanced recruitment of leukocytes to dysfunctional endothelium [1]. An important early event preceding the development of atheromatous lesions is the infiltration of the arterial subendothelial intima by macrophages/monocytes [2]. Interendothelial adherens

\footnotetext{
* Correspondence: Mehran.Haidari@uth.tmc.edu

'Department of Internal Medicine, Division of Cardiology, The University of Texas Medical School at Houston, 77030 Houston, TX, USA

${ }^{2}$ Texas Heart Institute at St. Luke's Episcopal Hospital, PO Box 20345 C1000, 77030 Houston, TX, USA
}

junctions (AJs) that maintain endothelial barrier function are largely composed of vascular endothelial cadherin (VE-cad), an endothelium-specific member of the cadherin family of adhesion proteins. Through its cytoplasmic domain, VE-cad binds to several proteins including p120, $\beta$-catenin, and plakoglobin $[3,4]$ that in turn bind $\alpha$-catenin, which links VE-cad to the actin cytoskeleton [5]. Tyrosine phosphorylation of VE-cad disrupts endothelial AJs by causing the dissociation of catenins from VE-cad and thus facilitates the diapedesis of leukocytes [6,7]. Myosin light chain (MLC) phosphorylation has a critical role in increasing the permeability of endothelial 
cells [8]. Recently, we showed that MLC phosphorylation mediates the tyrosine phosphorylation of VE-cad induced by the interaction of monocytes with endothelial cells, leading to the enhanced transendothelial migration (TEM) of monocytes [9]. Accelerated atherosclerosis is the leading cause of morbidity and mortality in diabetic patients [10]. Hyperglycemia has been implicated as an underlying cause of cardiovascular, retinal, and renal complications in diabetic patients; however, the mechanisms are not known. Hyperglycemia increases the adhesion of leukocytes to endothelial cells [11] possibly as the result of the stimulatory effect of hyperglycemia on the expression of adhesion molecules on the surface of endothelial cells $[12,13]$. In addition, high glucose levels increase the in vitro TEM of monocyte-like HL-60 cells [14], although this effect has been attributed to an increase in the phosphorylation of platelet-endothelial cell adhesion molecule-1(PECAM-1). It has been demonstrated that high concentration of glucose mediates an increase in permeability of endothelial cells to albumin by activation of protein kinase $C$ [15]. However, the integrity of AJs is a characteristic of endothelial barrier that regulates TEM of monocytes [6,7] and might be independent of permeability of endothelial cells to albumin. The molecular mechanisms underlying the effect of high concentration of glucose on integrity of endothelial AJs and TEM of monocytes has not been fully explored. In our study, we hypothesized that high concentrations of glucose disintegrate endothelial AJs and facilitate the TEM of monocytes through the protein kinase C-mediated tyrosine phosphorylation of VE-cad.

\section{Materials and methods Reagents}

Phospho-specific and nonphospho-specific antibodies against Src (pY416), proline-rich tyrosine kinase-2 (Pyk2) (pY402), glycogen synthase kinase 3- $\beta$ (GSK3 $\beta$, Ser 9), $\beta$-catenin, ERK1/2, MYPT, GAPDH and cyclin D1 were purchased from Abcam. Phospho-specific and nonphospho-specific antibodies against VE-cadherin (Y731) and monoclonal 4G10 anti-phosphotyrosine $\mathrm{Ab}$ were purchased from Invitrogen. Monoclonal phosphoantibody against MLC and specific antibody against MLC were purchased from Sigma-Aldrich. Mouse IgG was purchased from Southern Biotech. Cytochalasin D, 3O-methyl-D-glucose, mannitol, D-glucose, phorbol myristate acetate (PMA), forskolin, and protein kinase A inhibitor H89 were purchased from Calbiochem. Premade recombinant adenoviruses for dominant-negative (DN)protein kinase $C(\mathrm{PKC})-\alpha$, null control, and green fluorescent protein (GFP) and ViraDuctin adenovirus transduction reagents were purchased from Cell Biolabs, Inc. Premade recombinant adenoviruses for DN-PKC- $\beta$ and DN-PKC- $\delta$ were purchased from Applied Biological
Materials. The efficacy of all recombinant adenoviruses was previously tested $[9,16,17]$. The luciferase reporters, which contain either wild-type (TOPflash) or mutated (FOPflash) binding sites for the lymphoid enhancer factor1/T-cell specific transcription factor (Lef-1/TCF) complex were purchased from Millipore. The mutant construct for MLC, in which Thr18 and Ser19 were replaced with alanines (A-A-MLC) so that the protein could not be phosphorylated, was a generous gift from Dr. Andreas Kapus, University of Toronto, Toronto, Canada, [18].

\section{Cells}

Human umbilical vein endothelial cells (HUVECs) and human acute monocytic leukemia (THP-1) cells were purchased from American Type Culture Collection. Human aortic endothelial cells (HAECs) were purchased from Lonza. HUVECs and HAECs were grown in Lonza's EGM-2-MV medium on collagen-coated $(20 \mu \mathrm{g} / \mathrm{ml})$ tissue culture dishes. HUVECs and HAECs from fewer than 4 generations were used for all experiments. THP-1 cells were maintained in Roswell Park Memorial Institute (RPMI) 1640 medium supplemented with $10 \%$ heatinactivated fetal calf serum (FCS). A single-donor human peripheral blood buffy coat was purchased from the Gulf Coast Regional Blood Center (Houston, TX, USA) and used for isolation of peripheral blood monocytes.

\section{Western blotting}

HUVECs were grown to confluency in $35-\mathrm{mmol} / \mathrm{l}$ dishes or 6-well plates. Cells were extracted in radioimmunoprecipitation assay (RIPA) buffer, which contained 0.1\% SDS, $1 \%$ deoxycholate, $1 \% \mathrm{NP}-40,10 \mathrm{mmol} / \mathrm{l}$ sodium phosphate, $150 \mathrm{mmol} / \mathrm{l} \mathrm{NaCl}, 2 \mathrm{mmol} / \mathrm{l}$ EDTA, $50 \mathrm{mmol} / \mathrm{l}$ $\mathrm{NaF}, 5 \mathrm{mmol} / \mathrm{l}$ sodium pyrophosphate, $0.1 \mathrm{mmol} / \mathrm{l}$ sodium vanadate, $2 \mathrm{mmol} / \mathrm{l}$ PMSF, $0.1 \mathrm{mg} / \mathrm{ml}$ leupeptin, and 100 $\mathrm{KIU} / \mathrm{ml}$ aprotinin. Samples were loaded onto an SDSPAGE gel and run at $150 \mathrm{~V}$ for $1 \mathrm{~h}$. The proteins were then transferred onto nitrocellulose paper at $300 \mathrm{~mA}$ for $1.5 \mathrm{~h}$, followed by Western blot analysis. Blots were blocked with 5\% dry milk in $0.1 \%$ Tween 20 in PBS for $1 \mathrm{~h}$ at room temperature. The primary antibodies were used at a dilution of 1:500 to 1:1000. All antibodies were added for $1 \mathrm{~h}$ at room temperature or overnight at $4^{\circ} \mathrm{C}$. After washing, the appropriate secondary antibodies (Pierce Biotechnology, Inc., Rockford, IL, USA) were added at a dilution of 1:10 000 for $1 \mathrm{~h}$ at room temperature. After extensive washing, blots were developed with the Super Signal enhanced chemiluminescence kit (Pierce) and visualized on Kodak-AR film.

\section{Immunoprecipitation}

Cells were grown to confluency, washed gently with icecold PBS twice, and lysed in $1 \mathrm{ml}$ of RIPA lysis buffer. After $10 \mathrm{~min}$ on ice, cell lysates were collected and 
precleared for $30 \mathrm{~min}$ at $4^{\circ} \mathrm{C}$ with protein A-agarose. After centrifugation $\left(14000 \times g, 15 \mathrm{~s}\right.$ at $\left.4^{\circ} \mathrm{C}\right)$, the supernatants were incubated with primary antibodies $(1 \mu \mathrm{g} / \mathrm{mg}$ lysate) overnight at $4^{\circ} \mathrm{C}$ with continuous mixing. Protein A-agarose $(40 \mu \mathrm{l})$ was added to the lysate. After $2 \mathrm{~h}$ at $4^{\circ} \mathrm{C}$, the beads were washed 3 times in lysis buffer, and proteins were eluted by boiling in SDS-sample buffer containing 4\% 2-mercaptoethanol (Bio-Rad, Hercules, CA, USA). The samples were analyzed by SDS-PAGE.

\section{Transduction of adenovirus}

The conditions used for the transduction of recombinant adenoviruses were optimized by using adenovirus encoding GFP. All reagents and kits, including transduction reagents, an adenovirus purification kit, and an adenovirus titration kit, were purchased from Cell Biolabs, Inc. After purification, the titration of each recombinant adenovirus was determined by an ELISA titrating kit. HUVECs were seeded into 6-well plates for $24 \mathrm{~h}$ until they reached $80 \%$ confluence. According to the manufacturers' protocol, adenovirus was transduced into cells by using ViraDuctin (Cell Biolabs, Inc.). HUVECs were infected with adenoviral vectors with a multiplicity of infection (MOI) of 100 plaque-forming units per cell in the presence of ViraDuctin. After incubation with viral particles for $48 \mathrm{~h}$, the cells were assessed for the expression of the transduced genes.

\section{Transfection of plasmids}

The vector pcDNA3.1/CT-GFP TOPO (Invitrogen) was used to optimize the transfection of plasmids into HUVECs. Plasmids were transfected into cells by using Lipofectamine 2000 (Invitrogen). Empty pcDNA3.1 vector was transfected as controls. Cells were collected $48 \mathrm{~h}$ after transfection with plasmids.

\section{Immunofluorescence studies}

Cells were grown in wells of 4-chamber culture collagencoated slides. Cells were fixed in $4 \%$ paraformaldehyde for 15 min at $4^{\circ} \mathrm{C}$, washed with PBS, and permeabilized for 5 min with $0.1 \%$ Triton-X-100. After blocking with PBS $+2 \%$ BSA $+0.1 \%$ Tween-20, cells were incubated with primary antibody against $\beta$-catenin and goat antirabbit IgG for $45 \mathrm{~min}$ each. Images were acquired by MicroSuite FIVE software (Olympus Soft Imaging Solutions, Golden, CO, USA) with an Olympus BX61 motorized microscope (Olympus America, Center Valley, PA, USA).

\section{TEM assay}

A kit from Cell Biolabs, Inc. was used for TEM assays according to the manufacturer's instructions. THP-1 cells $\left(25 \times 10^{6}\right.$ each) were resuspended in $1 \mathrm{ml}$ of complete medium and incubated for $1 \mathrm{~h}$ at $37^{\circ} \mathrm{C}$ in the presence of $50 \mu \mathrm{g} / \mathrm{ml}$ calcein-AM (Molecular Probes, Invitrogen).
After the cells were labeled, they were resuspended at a concentration of $1 \times 10^{6} \mathrm{cell} / \mathrm{ml}$ in DMEM. The lower chamber was filled with assay medium plus $10 \mathrm{ng} / \mathrm{ml}$ of monocyte chemotactic protein (MCP)-1. THP-1 cells $\left(1.5 \times 10^{5}\right.$ in $\left.150 \mu \mathrm{l}\right)$ were added to the upper compartment of transwell chambers with $6.5-\mathrm{mm}$ diameter and $5-\mu \mathrm{m}$ pores for $2 \mathrm{~h}$. The cells that spontaneously detached from the undersurface of the filter were removed by the swab and were quantified with an Ultra384 plate reader (Tecan) by using 485 and $535 \mathrm{~nm}$ excitation and emission filters, respectively.

\section{Luciferase reporter assay}

Briefly, HUVECs $\left(1.5 \times 10^{4}\right)$ were seeded in a 12 -well plate and were transiently transfected with $0.3 \mu \mathrm{g}$ of TOPflash or FOPflash along with $10 \mathrm{ng}$ of pRL-SV40 (Promega) by using Lipofectamine 2000 (Invitrogen). After $48 \mathrm{~h}$, the cells were treated with glucose $(12.5,25$, or $50 \mathrm{mM}, 24 \mathrm{~h}$ ), PMA (50 nM, $8 \mathrm{~h}), \mathrm{LiCl}(10 \mathrm{mM}, 8 \mathrm{~h})$. Cells were then lysed, and luciferase activity was determined by using a Dual-Luciferase ${ }^{\odot}$ Reporter Assay System (Promega). The luciferase activity of each sample was normalized with that of Renilla, used for monitoring transfection efficiency.

\section{PKC total activity}

PKC activity was measured by using a MESACUP protein kinase assay kit (MBL International), which is based on an enzyme-linked immunosorbent assay, according to the manufacturer's protocol. Briefly, subconfluent HUVECs were washed 3 times with cold phosphatebuffered saline (PBS), scraped with a rubber policeman, and suspended in $1 \mathrm{~mL}$ of cold sample preparation buffer $(50 \mathrm{mM}$ Tris- $\mathrm{HCl}$ [pH 7.5], $5 \mathrm{mM}$ EDTA, $10 \mathrm{mM}$ EGTA, 50 mM 2-mercaptoethanol, $1 \mathrm{mM}$ PMSF, $10 \mathrm{mM}$ benzamidine). The phosphatidylserine (PS) peptide plate was phosphorylated by incubation with $30 \mu \mathrm{g} / \mathrm{mL}$ cell lysate, $3 \mathrm{mM} \mathrm{MgCl}, 2 \mathrm{mM} \mathrm{CaCl} 2,0.1 \mathrm{mM}$ ATP, $50 \mu \mathrm{g} / \mathrm{mL}$ phosphatidylserine, $0.5 \mathrm{mM}$ EDTA, $1 \mathrm{mM}$ EGTA, $5 \mathrm{mM}$ 2-mercaptoethanol, and $25 \mathrm{mM}$ Tris- $\mathrm{HCl}(\mathrm{pH} 7.0)$ at $25^{\circ} \mathrm{C}$ for $10 \mathrm{~min}$. The biotinylated monoclonal antibody 2B9 was used to bind the phospho-PS peptide and was subsequently detected with peroxidase-conjugated streptavidin. A peroxidase substrate was then added to the microwells, and color intensity was measured spectrophotometrically at $492 \mathrm{~nm}$.

\section{Statistics}

Transmigration data were analyzed by analysis of variance (ANOVA), and a 2-sample Student $t$ test was used to calculate statistical significance (Excel, Microsoft Corp., Houston, TX, USA). All experiments were repeated at least 3 times. A probability $(P)$ value $<0.05$ was considered significant. 


\section{Results}

Treatment of Endothelial Cells with High-Concentration Glucose Leads to the Disintegration of Endothelial AJs

The treatment of HUVECs with high concentrations of D-glucose, otherwise referred to as glucose, for 24 hours increased tyrosine phosphorylation of VE-cad in a dosedependent manner (Figure 1A). In addition, phosphorylation of the tyrosine kinases Src and Pyk2 that regulate the tyrosine phosphorylation of VE-cad was also increased in HUVECs treated with high concentrations of glucose (Figure 1A). To confirm tyrosine phosphorylation of VE-cadherin after treatment of HUVECs with high glucose VE-cadherin was immunoprecipitated and then tyrosine phosphorylation was tested with monoclonal 4G10 anti-phosphotyrosine Ab. As indicated in Figure 1B tyrosine residues of VE-cadherin was phosphorylated after treatment of HUVECs with high concentration of glucose.
When HUVECs were treated with $25 \mathrm{mM}$ glucose, the VE-cad- $\beta$-catenin complex was dissociated (Figure 1C). In addition, the TEM of THP-1 cells (a monocytic leukemia cell line) was significantly increased in a dose-dependent manner in HUVECs treated with high concentrations of glucose (Figure 1D). Similar studies with primary human peripheral blood monocytes showed comparable results, indicating that these findings are not specific to THP-1 cells (Figure 1E). In contrast to high-concentration glucose, neither mannitol nor 3-Omethyl-D glucose (a nonmetabolizable glucose analogue) altered VE-cad tyrosine phosphorylation in HUVECs after 24 hours (Figure 1F and G). Similar to HUVECs treated with high concentrations of glucose, human aortic endothelial cells (HAECs) treated with high concentrations of glucose for $24 \mathrm{~h}$ also showed a dose-dependent increase in VE-cad tyrosine phosphorylation (Figure $1 \mathrm{H}$ ). These

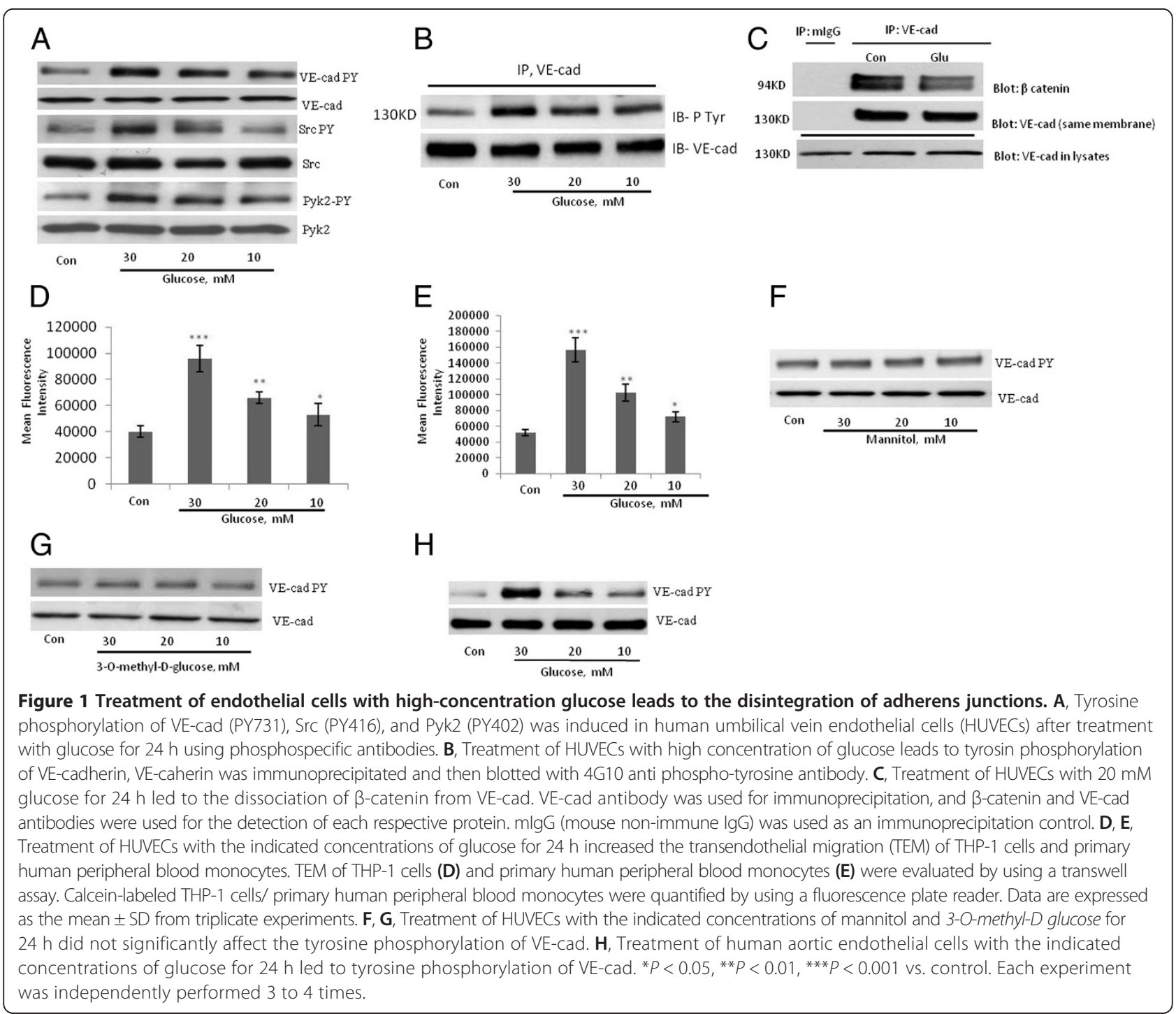


results suggest that high-concentration glucose disrupts the integrity of endothelial AJs, which is associated by an increase in the tyrosine phosphorylation of VE-cad.

\section{High-Concentration Glucose-Induced VE-cad Tyrosine Phosphorylation Is Mediated by PKC- $\beta$}

Activation of PKC contributes to microvascular barrier dysfunction [19] and inhibition of PKC- $\beta$ reverses cardiac microvascular barrier dysfunction in diabetic rats [20]. We recently demonstrated that the treatment of HUVECs with the PKC activator PMA increases the tyrosine phosphorylation of VE-cad, the dissociation of $\beta$-catenin from the VE-cad complex, and the TEM of invasive breast cancer cells, MDA-MB-231 cells [21]. Therefore, we hypothesized that PKC plays a role in the high-concentration glucose-induced disruption of endothelial AJs. We found that the treatment of HUVECs with high-concentrations of glucose led to a dose-dependent increase in the activation of endothelial PKC (Figure 2) and the phosphorylation of ERK (Figure 2B), which leads to MLC phosphorylation and VE-cad tyrosine phosphorylation [9]. In addition, high-concentration glucose-induced tyrosine phosphorylation of VE-cad was attenuated when HUVECs were treated with bisindolylmaleimide, an inhibitor of PKC (Figure 2C). Treatment of HUVECs with $50 \mathrm{nM}$ PMA for $48 \mathrm{~h}$ resulted in a significant reduction in PKC activity (Figure 2D). Furthermore, when HUVECs were depleted of PKC by lengthy treatment with PMA (48 h), the high-concentration glucoseinduced TEM of THP-1 cells was reduced (Figure 2E). In addition, the inhibition of intracellular calcium by BAPTA-AM (N',N'-tetraacetic acid) attenuated the highconcentration glucose-induced tyrosine phosphorylation of VE-cad (Figure 3A), suggesting a role for conventional PKC (ie, PKC- $\alpha,-\beta 1,-\beta 2$, and $-\gamma$ ) in the high-concentration glucose-induced tyrosine phosphorylation of VE-cad. Similar experiments with HAECs demonstrated that PKC mediates high glucose-induced tyrosine phosphorylation of VE-cad (data not shown). When PKC- $\beta$, PKC- $\alpha$, or PKC- $\delta$ was inhibited by

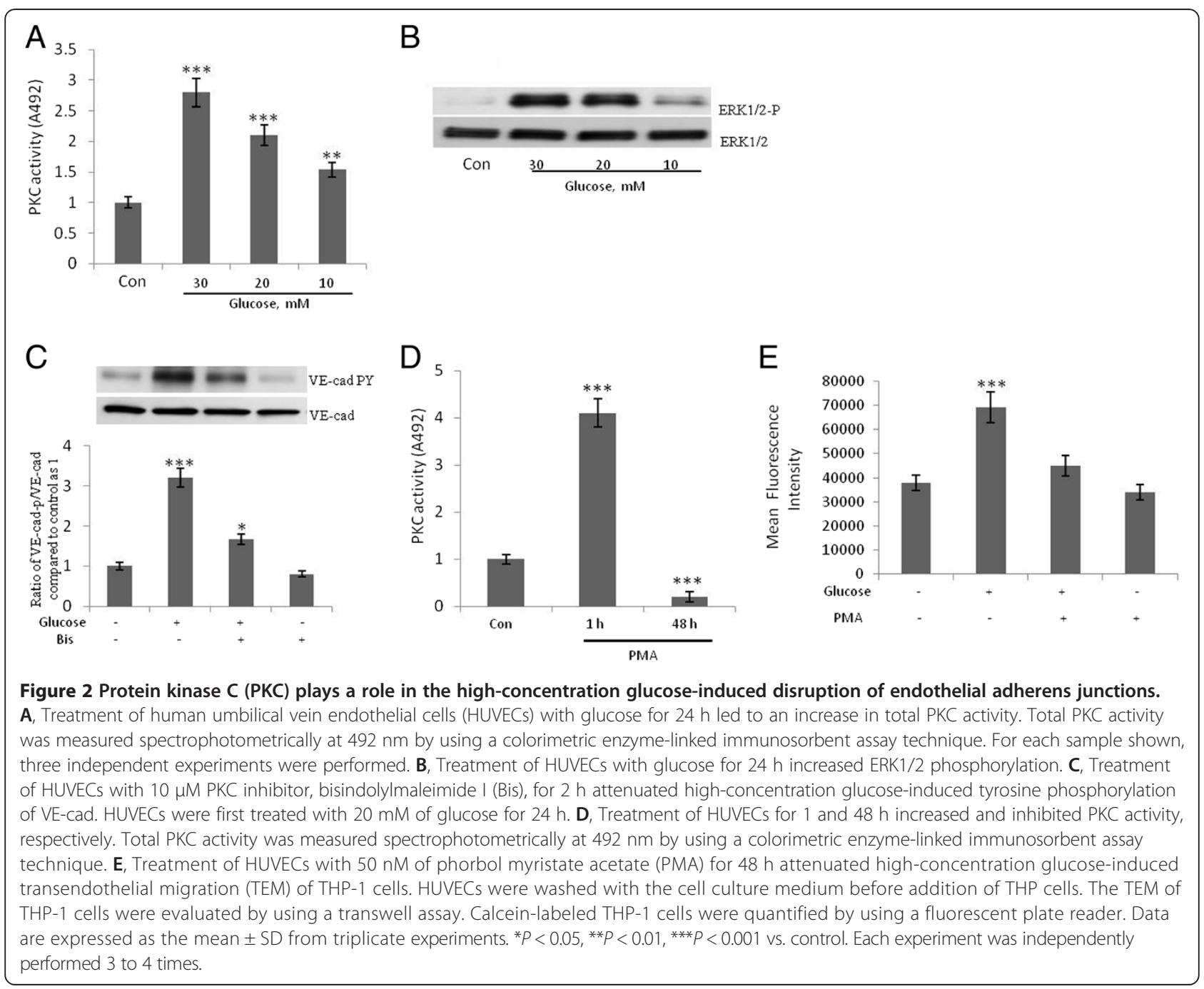




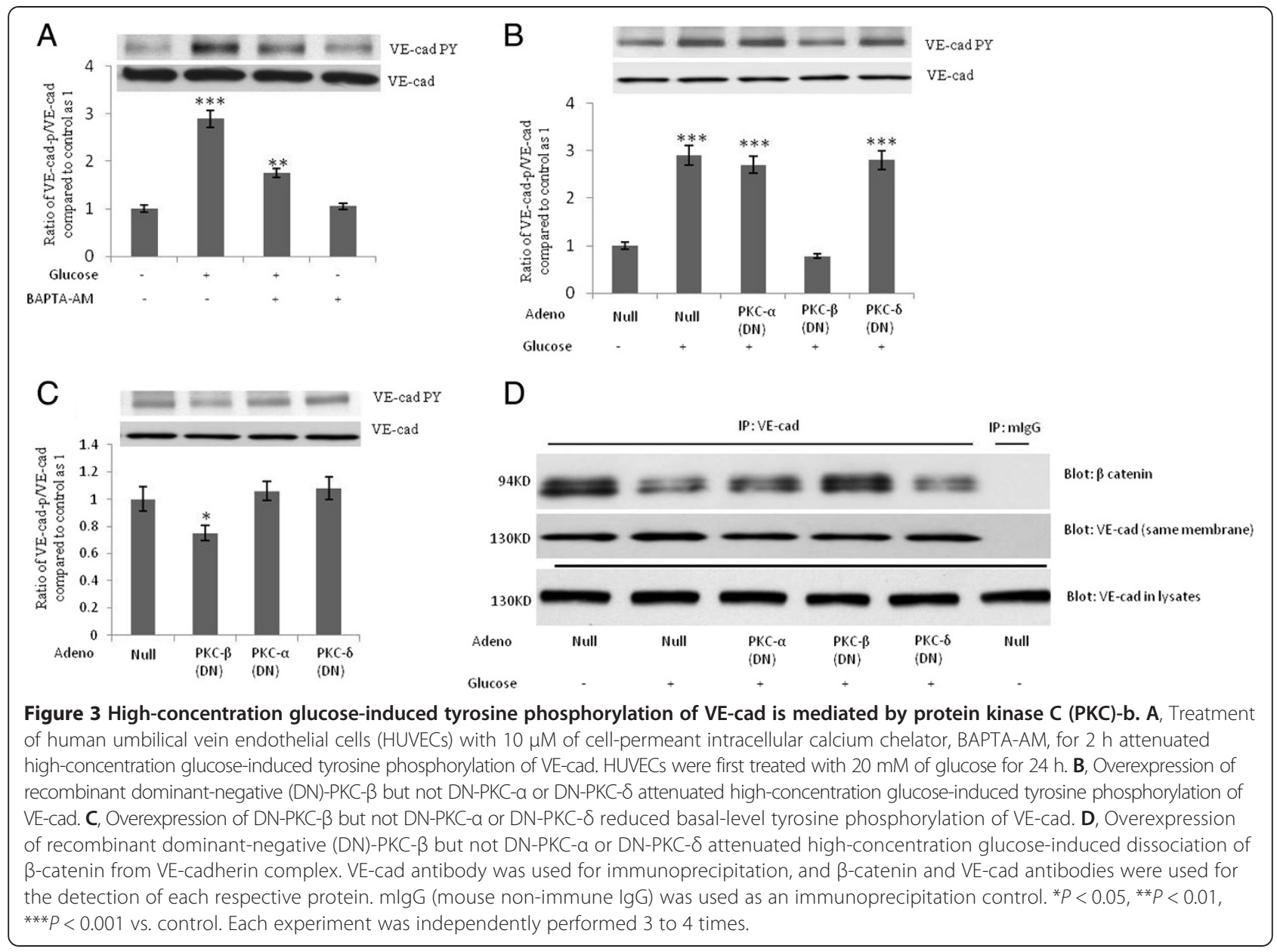

overexpression of the corresponding dominant-negative protein, only $\mathrm{PKC}-\beta$ abolished high-concentration glucose-induced VE-cad tyrosine phosphorylation (Figure $3 \mathrm{~B}$ ). We also found that the inhibition of PKC- $\beta$ but not the inhibition of PKC- $\alpha$ or PKC- $\delta$ by overexpression of the corresponding dominant-negative protein inhibited basal levels of VE-cad tyrosine phosphorylation by $25 \%$ (Figure $3 C$ ). Inhibition of PKC- $\beta$ but not of PKC- $\alpha$ or PKC- $\delta$ by over expression of the corresponding dominant-negative protein resulted in suppression of high glucose induced dissociation of $\beta$-catenin from VE-cadherin complex (Figure 3D). These results suggest that high-concentration glucose-induced VE-cad tyrosine phosphorylation is mediated by PKC- $\beta$.

\section{Phosphorylation of MLC Mediates Tyrosine Phosphorylation of VE-cad Induced by High-Concentration Glucose}

Because MLC phosphorylation plays a crucial role in VE-cad tyrosine phosphorylation induced by the interaction of monocytes with endothelial cells [9] we studied the role of MLC phosphorylation and actin polymerization in the high-concentration glucose-induced tyrosine phosphorylation of VE-cad. The high-concentration glucose-induced tyrosine phosphorylation of VE-cad was accompanied by an increase in the phosphorylation of MLC and the regulatory subunit of MLC phosphatase (MYPT, Figure 4A). Phosphorylation of MYPT inhibits MLC phosphatase [22]. A nonphosphorylatable mutant construct for MLC in which Thr18 and Ser19 are replaced with alanines (AA-MLC) was used to study the role of MLC phosphorylation in high-concentration glucoseinduced tyrosine phosphorylation of VE-cad [9,17]. The inhibition of MLC phosphorylation by the overexpression of DN-AA-MLC (GFP transfection rate, 40\%; Figure 4B) and the inhibition of actin polymerization by cytochalasin $\mathrm{D}(1 \mu \mathrm{M}, 2 \mathrm{~h}$; Figure $4 \mathrm{C})$ attenuated the high-concentration glucose-induced tyrosine phosphorylation of VE-cad, suggesting a crucial role for MLC phosphorylation in mediating the effects of high-concentration glucose on the tyrosine phosphorylation of VE-cad. Studies with HAECs indicated that induction of VE-cad tyrosine phosphorylation by high glucose is mediated by MLC phosphorylation (data not shown). Given that PKA inhibits MLC phosphorylation [23] we examined the effects of PKA 
A
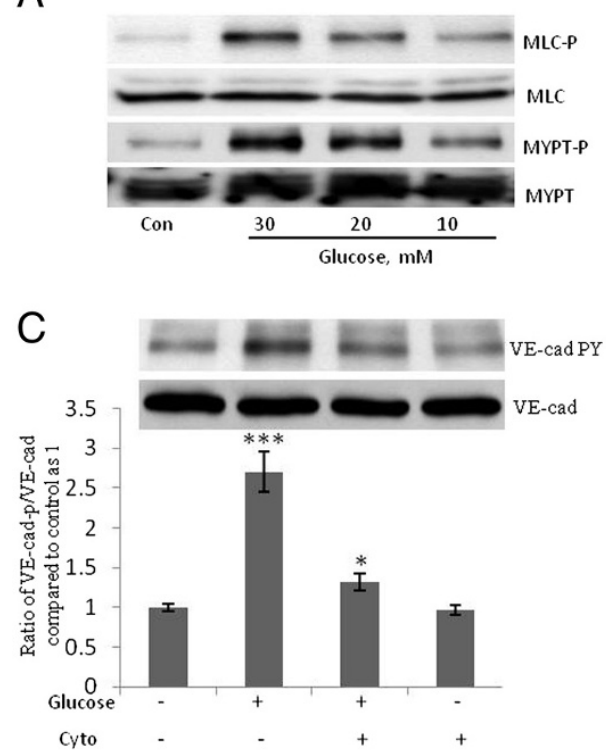

$\mathrm{E}$

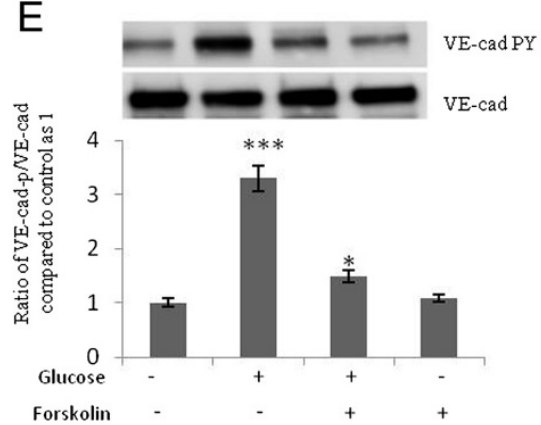

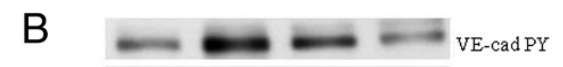

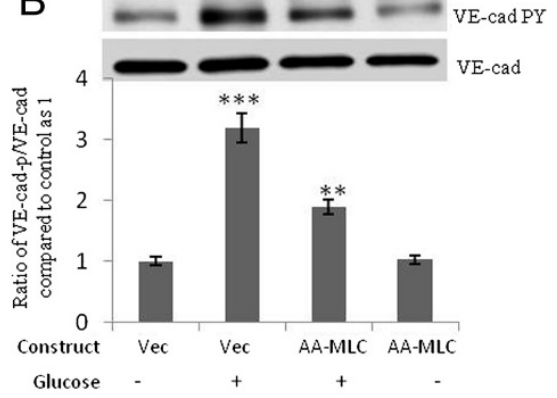

$\mathrm{D}$

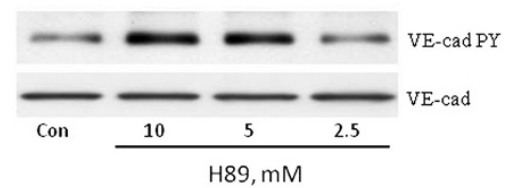

Figure 4 Phosphorylation of myosin light chain (MLC) mediates high-concentration glucose-induced tyrosine phosphorylation of VE-cad. A, Treatment of human umbilical vein endothelial cells (HUVECs) with glucose for $24 \mathrm{~h}$ led to phosphorylation of MLC and MLC phosphatase regulatory subunit (MYPT). B, High-concentration glucose-induced VE-cad tyrosine phosphorylation was attenuated in HUVECS overexpressing mutant MLC (AA-MLC), in which Thr18 and Ser19 are replaced with alanines. HUVECs were transfected with the indicated constructs and, after 48 h, were treated with 20 mM glucose for 24 h. C, Cytochalasin D suppressed high-concentration glucose-induced tyrosine phosphorylation of VE-cad. HUVECs were treated with $20 \mathrm{mM}$ glucose for $24 \mathrm{~h}$ and then $1 \mu \mathrm{M}$ cytochalasin D for $2 \mathrm{~h}$. D. Treatment of HUVECs with protein kinase A inhibitor H89 for $2 \mathrm{~h}$ led to tyrosine phosphorylation of VE-cad. E, Treatment of HUVECs with $10 \mu \mathrm{M}$ forskolin for $2 \mathrm{~h}$ (an activator of adenylate cyclase) attenuated high-concentration-induced tyrosine phosphorylation of VE-cad. HUVECs were first treated with $20 \mathrm{mM}$ of glucose for $24 \mathrm{~h}$. ${ }^{*} P<0.05$, ${ }^{* * *} P<0.001$ vs. control. Each experiment was independently performed 3 to 4 times.

inhibitor H89 on VE-cad phosphorylation. H89 increased VE-cad tyrosine phosphorylation in HUVECs in a dosedependent manner (Figure 4D). Furthermore, because the cAMP/PKA signaling pathway stabilizes the barrier property of endothelial cells $[24,25]$ we examined the effect of increasing the concentration of cAMP on the highconcentration glucose-induced tyrosine phosphorylation of VE-cad. In HUVECs treated with forskolin (an activator of adenylate cyclase), the high-concentration glucose-induced tyrosine phosphorylation of VE-cad was attenuated (Figure 5E). These results suggest that the high-concentration glucose-induced tyrosine phosphorylation of VE-cad is mediated by MLC phosphorylation.
High-Concentration Glucose Induces Phosphorylation of GSK3 $\beta$ and Transactivation of $\beta$-catenin-Responsive

\section{Genes}

Dissociation of AJs leads to the internalization of cadherinbound $\beta$-catenin and its accumulation in the perinuclear endocytic recycling compartment [26]. Upon stimulation of the wingless (Wnt) signaling pathway, glycogen synthase kinase-3 $\beta$ (GSK3 $\beta$ ), a protein that is part of the complex that regulates the proteasomal degradation of $\beta$-catenin, is inactivated/phosphorylated, and $\beta$-catenin is translocated to the nucleus where it associates with Lef-1/TCF to activate target gene transcription and biological responses $[27,28]$. 

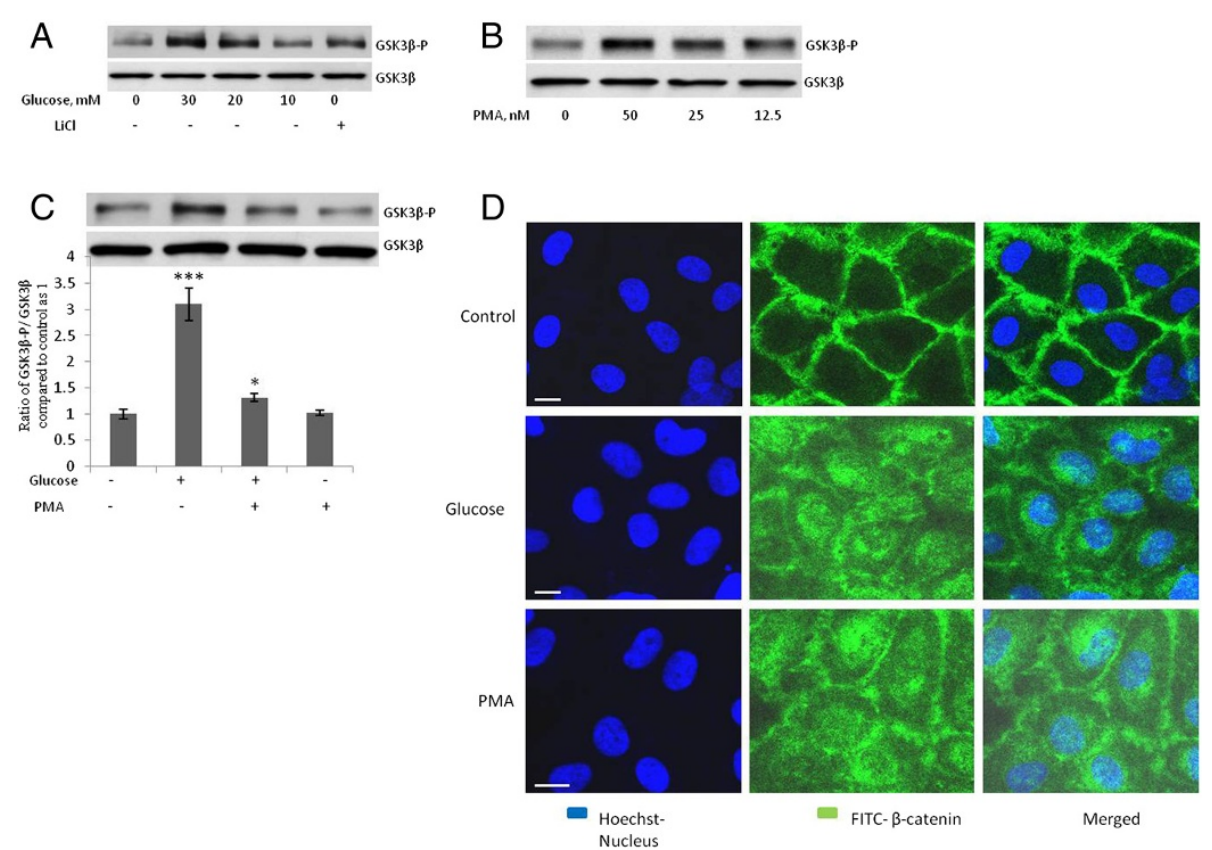

Figure 5 High-concentration glucose induces the phosphorylation of GSK $\beta$ (Ser9) and the intracellular accumulation of b-catenin. A, B Treatment of human umbilical vein endothelial cells (HUVECS) with glucose (10-30 mM, 24 h), LiCl (10 mM, 4 h), or PMA (12.5-50 nM, 4 h) increased phosphorylation of GSK3 $\beta$ (Ser 9). C, Treatment of HUVECs with $50 \mathrm{nM}$ of PMA for $48 \mathrm{~h}$ attenuated high-concentration-glucose-induced GSK3 $\beta$ phosphorylation. After treatment of the indicated samples with PMA for $48 \mathrm{~h}$, glucose was added to the indicated samples for $24 \mathrm{~h}$ before GSK3 $\beta$ (Ser 9) phosphorylation was evaluated. D, Treatment of HUVECs with $20 \mathrm{mM}$ of glucose for $24 \mathrm{~h}$ or $50 \mathrm{nM}$ of PMA for $4 \mathrm{~h}$ induced the translocation of $\beta$-catenin into the cytoplasm and nuleus of the cells. HUVECs were fixed with $4 \%$ paraformaldehyde and stained with primary rabbit polyclonal antibody against $\beta$-catenin and secondary FITC-conjugated goat anti-rabbit lgG antibody (green). Hoechst was used to stain the nuclei (blue). Bar $=10 \mu \mathrm{m}$. Magnification, $63 \mathrm{X}$. ${ }^{* *} P<0.001$, ${ }^{* *} P<0.01$, and ${ }^{*} P<0.05$ vs. control. Each experiment was independently performed 3 to 4 times.

To determine if Wnt- $\beta$-catenin pathway is activated after high-concentration glucose-induced dissociation of $\beta$-catenin from VE-cad, we studied the phosphorylation of GSK3 $\beta$ and the cellular localization of $\beta$-catenin. The treatment of HUVECs with high concentrations of glucose $(24 \mathrm{~h})$ or PMA $(4 \mathrm{~h})$ resulted in the dose-dependent inactivation/phosphorylation of GSK3 $\beta$ (Figure $5 \mathrm{~A}$ and $\mathrm{B}$ ). GSK3 $\beta$ was also phosphorylated when HUVECs were treated with $\mathrm{LiCl}$, a known inhibitor of GSK3 $\beta$ (Figure 5A). When HUVECs were depleted of PKC by lengthy treatment (48 h) with PMA, the high-concentration glucoseinduced phosphorylation of GSK3 $\beta$ was significantly reduced (Figure $5 \mathrm{C}$ ), suggesting that PKC mediates highconcentration glucose-induced GSK3 $\beta$ phosphorylation. The treatment of HUVECs with high-concentration glucose or PMA $(4 \mathrm{~h})$ resulted in the accumulation of intracellular $\beta$-catenin (Figure 5D).

To determine whether high-concentration glucose induces the transactivation of $\beta$-catenin-responsive genes, we performed luciferase reporter assays using luciferase reporters that contain either the wild-type (TOPflash) or mutated (FOPflash) binding sites for the Lef-1/TCF complex, which have been widely used to characterize $\beta$-catenin-TCF-dependent gene expression [29]. High- concentration glucose, PMA, or $\mathrm{LiCl}$ significantly increased TOPflash Lef-1/TCF-responsive promoter activity but had no effect on FOPflash promoter activity (Figure 6A). Furthermore, the treatment of HUVECs with highconcentration glucose, PMA, or $\mathrm{LiCl}$ increased the protein expression of cyclin D1, which is encoded by a $\beta$-cateninresponsive gene (Figure $6 \mathrm{~B}$ and $\mathrm{C}$ ). In addition, the mRNA expression of another $\beta$-catenin-responsive gene, urokinase plasminogen activator, u-PA but not the endothelial cell marker CD31, was also increased after HUVECs were treated with high-concentration glucose, PMA, or $\mathrm{LiCl}$ (Figure 6D). These results suggest that the $\mathrm{Wnt} / \mathrm{\beta}$ catenin pathway is activated in endothelial cells treated with high concentrations of glucose.

\section{Discussion}

In our study, we showed that the treatment of endothelial cells with high-concentration glucose led to the tyrosine phosphorylation of VE-cad, the dissociation of $\beta$-catenin from the VE-cad complex, and the increased TEM of monocytes. Furthermore, the disruption of endothelial AJ integrity induced by high-concentration glucose was mediated by PKC- $\beta$-dependent MLC phosphorylation and was associated with the activation of the 


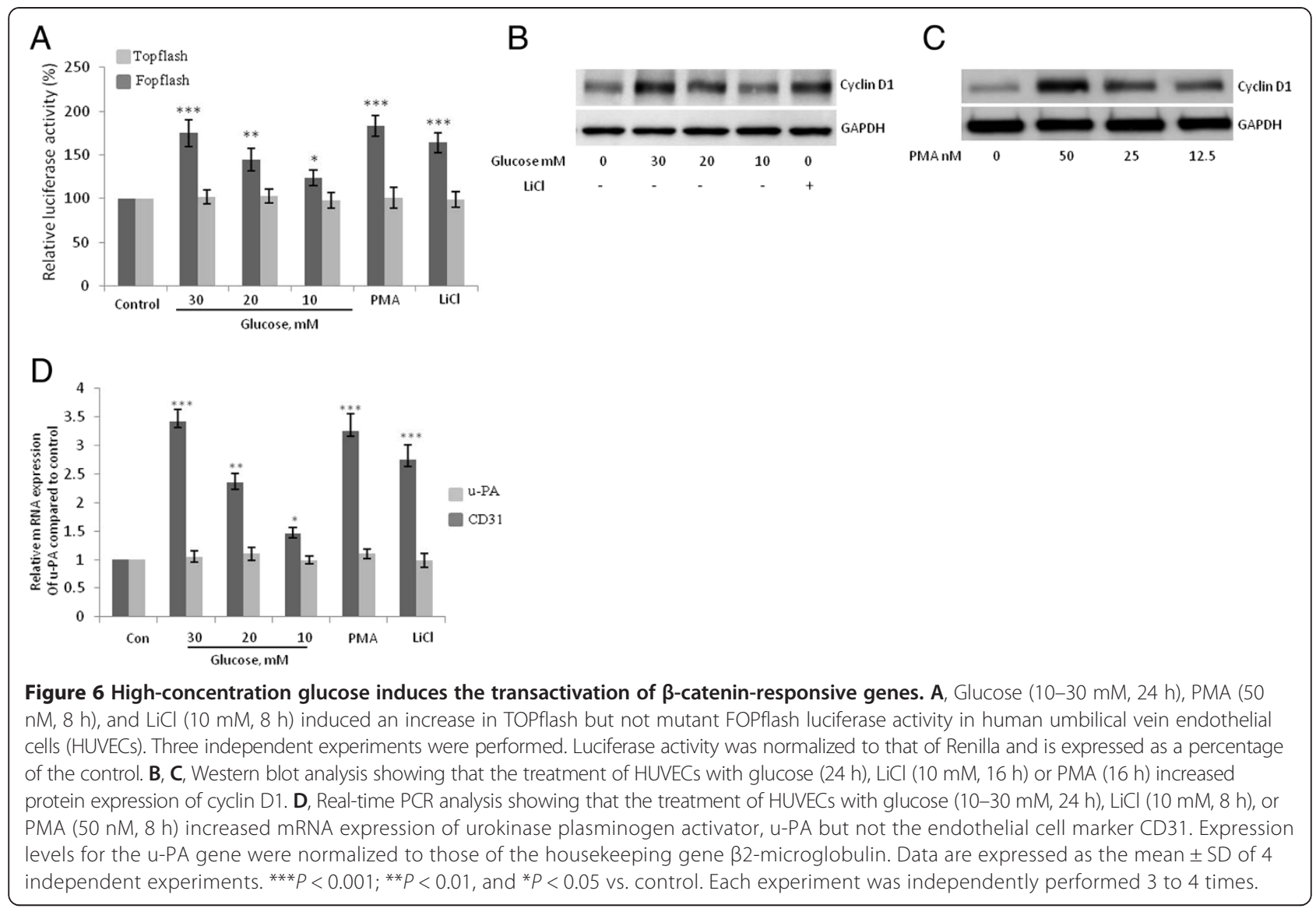

Wnt/ß-catenin signaling pathway. Our findings provide evidence of a mechanism that may underlie the increased risk of atherosclerosis in patients with diabetes.

Recent studies in low-density lipoprotein receptordeficient mice, which are hyperglycemic but exhibit no marked dyslipidemia when compared with nondiabetic controls, showed that diabetes in the absence of diabetesinduced hyperlipidemia is associated with the accelerated formation of atherosclerotic lesions, similar to what is seen in fat-fed nondiabetic mice [30]. The observed increase in the adhesion of leukocytes to endothelial cells has been attributed to the hyperglycemia-induced overexpression of endothelial adhesion molecules [31]. Our studies suggest that the high-concentration glucose-induced disruption of endothelial AJs may also be a mechanism underlying accelerated atherosclerosis in diabetes. Based on the results of our previous studies $[9,16,17,32]$ we have developed a hypothetical model [9] for how the interaction of monocytes with endothelial cells leads to the enhancement of monocyte TEM. We showed that increased phosphorylation of MLC by inhibition of MLC phosphatase leads to tyrosine phosphorylation of VE-cad [9]. Several signaling pathways regulate MLC phosphorylation, including PKC, Rho-family GTPases, and
RAS [32-37]. Therefore, we logically speculated that the same pathways regulate VE-cad tyrosine phosphorylation. Our previous and current findings support this hypothesis $[9,16,17]$. However, further investigation is needed to identify the underlying mechanisms by which high-glucose-induced phosphorylation of MLC leads to VE-cad tyrosine phosphorylation. It is possible that MLC phosphorylation and actomyosin contraction trigger not only mechanical and cytoskeletal changes in endothelial cells but also lead to the redistribution of kinases and phosphatases that regulate VE-cad tyrosine phosphorylation. Such a mechanism may contribute to the phosphorylation of VE-cad in endothelial cells treated with high-concentration glucose. Previous studies showed that actin polymerization, RhoA activity, and myosin activity are required for the recruitment and accumulation of junctional complex components [38,39]. Two nonreceptor tyrosine kinases that regulate the tyrosine phosphorylation of VE-cad-Src and Pyk2 [9] -associate with VE-cad [40,41]. We showed that the interaction of monocytes with endothelial cells or the overexpression of constitutively active HRas in endothelial cells recruits Src to the VE-cad complex [9]. In this study, we showed that the treatment of HUVECs with high-concentration glucose resulted in the 
phosphorylation/inhibition of GSK3 $\beta$, which in turn led to the accumulation of intracellular $\beta$-catenin, an increase in TCF-responsive promoter (TOPflash) activity, and the transactivation of the $\beta$-catenin-responsive genes cyclin $\mathrm{D} 1$ and $\mathrm{u}-\mathrm{PA}$. It has been shown that $\mathrm{u}-\mathrm{PA}$ and its cell surface receptor, $\mathrm{u}-\mathrm{PAR}$, are overexpressed in atherosclerotic plaques and may contribute to vascular wall inflammation [42]. In addition, in vivo microscopy analysis of the cremaster muscle in mice showed that endothelial u-PA promotes the TEM of neutrophils [43]. Vascular endothelial growth factor (VEGF), which is known to increase VE-cad tyrosine phosphorylation [44], induces the hyperpermeability of endothelial cells by activating the $\mathrm{u}-\mathrm{PA} / \mathrm{u}-\mathrm{PAR}$ system through the transcriptional activation of $\beta$-catenin, thus increasing $u$-PAR expression [45]. Moreover, $\mathrm{u}-\mathrm{PA}$ increases the permeability of endothelial cells [46]. Interestingly, u-PA activates ERK in many different cell types including endothelial cells $[47,48]$. Furthermore, uPA promotes cellular migration by initiating a u-PAR-dependent signaling cascade in which Ras, MEK, ERK, and MLC kinase serve as essential downstream effectors [49].

These findings suggest that u-PA may initiate the signal transduction that leads to VE-cad tyrosine phosphorylation and the disruption of AJs. Additional studies are needed to determine the role of high-concentration glucose-induced $\mathrm{u}-\mathrm{PA}$ expression in endothelial $\mathrm{AJ}$ integrity.

\section{Conclusions}

We showed that treatment of endothelial cells with highconcentration glucose leads to the PKC- $\beta$-mediated disruption of endothelial AJs and the activation of the Wnt/B-catenin signaling pathway. The results of this study provide supportive in vitro evidence for a possible molecular mechanism underlying the increased risk of atherosclerosis in diabetes.

\section{Competing interests}

The authors declare that they have no competing interests.

\section{Authors' contributions}

WZ carried out cell culture, western blot and protein kinase $\mathrm{C}$ assays. $\mathrm{MH}$ conceived of the study, carried out the cellular and molecular studies, prepared the manuscript pictures, performed statistical analysis, and drafted and finalized the manuscript. JW and RD participated in the design of the study and helped to draft and edit the manuscript. All authors read and approved the final manuscript.

\footnotetext{
Acknowledgments

The authors thank Dr. Andreas Kapus, University of Toronto, Toronto, Canada, for generously providing the A-A-MLC construct and Nicole Stancel, PhD, ELS, of the Texas Heart Institute at St. Luke's Episcopal Hospital, Houston, Texas, for editorial assistance.

This work was supported by a MacDonald General Research Fund (grant \# $11 \mathrm{RDM} 008$ ) to M.H.
}

Received: 21 February 2014 Accepted: 29 April 2014

Published: 15 July 2014

\section{References}

1. Libby P: Inflammation in atherosclerosis. Nature 2002, 420:868-874

2. Jongstra-Bilen J, Haidari M, Zhu SN, Chen M, Guha D, Cybulsky MI: Low-grade chronic inflammation in regions of the normal mouse arterial intima predisposed to atherosclerosis. J Exp Med 2006, 203:2073-2083.

3. Dejana E, Orsenigo F, Lampugnani MG: The role of adherens junctions and VE-cadherin in the control of vascular permeability. J Cell Sci 2008 121:2115-2122.

4. Vestweber D: VE-cadherin: the major endothelial adhesion molecule controlling cellular junctions and blood vessel formation. Arterioscler Thromb Vasc Biol 2008, 28:223-232.

5. Kemler R: From cadherins to catenins: cytoplasmic protein interactions and regulation of cell adhesion. Trends Genet 1993, 9:317-321.

6. Alcaide P, Newton G, Auerbach S, Sehrawat S, Mayadas TN, Golan DE, Yacono P, Vincent P, Kowalczyk A, Luscinskas FW: p120-Catenin regulates leukocyte transmigration through an effect on VE-cadherin phosphorylation. Blood 2008, 112:2770-2779.

7. Schulte D, Kuppers V, Dartsch N, Broermann A, Li H, Zarbock A, Kamenyeva O, Kiefer F, Khandoga A, Massberg S, Vestweber D: Stabilizing the VE-cadherin-catenin complex blocks leukocyte extravasation and vascular permeability. EMBO J 2011, 30:4157-4170.

8. Shen Q, Rigor RR, Pivetti CD, Wu MH, Yuan SY: Myosin light chain kinase in microvascular endothelial barrier function. Cardiovasc Res 2010, 87:272-280.

9. Haidari M, Zhang W, Chen Z, Ganjehei L, Warier N, Vanderslice P, Dixon R: Myosin light chain phosphorylation facilitates monocyte transendothelial migration by dissociating endothelial adherens junctions. Cardiovasc Res 2011, 92:456-465.

10. Vestweber D: Novel insights into leukocyte extravasation. Curr Opin Hematol 2012, 19:212-217.

11. Nathan DM, Lachin J, Cleary P, Orchard T, Brillon DJ, Backlund JY, O'Leary $\mathrm{DH}$, Genuth S: Intensive diabetes therapy and carotid intima-media thickness in type 1 diabetes mellitus. N Engl J Med 2003, 348:2294-2303.

12. Altannavch TS, Roubalova $K$, Kucera $P$, Andel M: Effect of high glucose concentrations on expression of ELAM-1, VCAM-1 and ICAM-1 in HUVEC with and without cytokine activation. Physiol Res 2004, 53:77-82.

13. Smolock AR, Mishra G, Equchi K, Equchi S, Scalia R: Protein kinase $C$ upregulates intercellular adhesion molecule-1 and leukocyte-endothelium interactions in hyperglycemia via activation of endothelial expressed calpain. Arterioscler Thromb Vasc Biol 2011, 31:289-296.

14. Rattan V, Shen Y, Sultana C, Kumar D, Kalra VK: Glucose-induced transmigration of monocytes is linked to phosphorylation of PECAM-1 in cultured endothelial cells. Am J Physio/ 1996, 271:E711-717.

15. Hempel A, Maasch C, Heintze U, Lindschau C, Dietz R, Luft FC, Haller H: High glucose concentrations increase endothelial cell permeability via activation of protein kinase C alpha. Circ Res 1997, 81:363-71.

16. Haidari M, Zhang W, Caivano A, Chen Z, Ganjehei L, Mortazavi A, Stroud C, Woodside DG, Willerson JT, Dixon RA: Integrin alpha2beta1 mediates tyrosine phosphorylation of vascular endothelial cadherin induced by invasive breast cancer cells. J Biol Chem 2012, 287:32981-32992.

17. Haidari M, Zhang W, Chen Z, Ganjehei L, Mortazavi A, Warier N, Vanderslice $P$, Dixon RA: Atorvastatin preserves the integrity of endothelial adherens junctions by inhibiting vascular endothelial cadherin tyrosine phosphorylation. Exp Cell Res 2012, 318:1673-1684

18. Di Ciano-Oliveira C, Lodyga M, Fan L, Szaszi K, Hosoya H, Rotstein OD, Kapus A: Is myosin light-chain phosphorylation a regulatory signal for the osmotic activation of the $\mathrm{Na}+-\mathrm{K}+-2 \mathrm{Cl}$ - cotransporter? Am J Physiol Cell Physio 2005, 289:C68-81.

19. Dang $L$, Seale JP, Qu X: High glucose-induced human umbilical vein endothelial cell hyperpermeability is dependent on protein kinase $C$ activation and independent of the $\mathrm{Ca} 2+-$ nitric oxide signalling pathway. Clin Exp Pharmacol Physiol 2005, 32:771-776

20. Wei L, Yin Z, Yuan Y, Hwang A, Lee A, Sun D, Li F, Di C, Zhang R, Cao F, Wang H: A. PKC-beta inhibitor treatment reverses cardiac microvascular barrier dysfunction in diabetic rats. Microvasc Res 2010, 80:158-165.

21. Haidari M, Zhang W, Wakame K: Reactive Oxygen Species Mediate Disruption of Endothelial Adherens Junction Induced by Invasive Breast Cancer Cells (a mechanism that is attenuated by Active Hexose Correlated Compound. AHCC Life Sci 2013, 18:994-1003. doi:10.1016/j.lfs.2013.10.027 
22. Kimura $K$, Ito $M$, Amano $M$, Chihara K, Fukata $Y$, Nakafuku M, Yamamori B, Feng J, Nakano T, Okawa K, Iwamatsu A, Kaibuchi K: Regulation of myosin phosphatase by Rho and Rho-associated kinase (Rho-kinase). Science 1996, 73:245-248

23. Aslam M, Hartel FV, Arshad M, Gunduz D, Abdallah Y, Sauer H, Piper HM, Noll T: CAMP/PKA antagonizes thrombin-induced inactivation of endothelial myosin light chain phosphatase: role of CPI-17. CardiovasC Res 2010, 87:375-384

24. Moore TM, Chetham PM, Kelly JJ, Stevens T: Signal transduction and regulation of lung endothelial cell permeability. Interaction between calcium and cAMP. Am J Physiol 1998, 275:L203-222.

25. Qiao J, Huang F, Lum H: PKA inhibits RhoA activation: a protection mechanism against endothelial barrier dysfunction. Am J Physiol Lung Cell Mol Physiol 2003, 284:L972-980.

26. Kam Y, Quaranta V: Cadherin-bound beta-catenin feeds into the Wnt pathway upon adherens junctions dissociation: evidence for an intersection between beta-catenin pools. PLoS One 2009, 4:e4580.

27. Huber $\mathrm{AH}$, Weis Wl: The structure of the beta-catenin/E-cadherin complex and the molecular basis of diverse ligand recognition by beta-catenin. Cell 2001, 105:391-402.

28. Nelson WJ, Nusse R: Convergence of Wnt, beta-catenin, and cadherin pathways. Science 2004, 303:1483-1487.

29. Molenaar $M$, van de Wetering M, Oosterwegel M, Peterson-Maduro J, Godsave S, Korinek V, Roose J, Destree O, Clevers H: XTcf-3 transcription factor mediates beta-catenin- induced axis formation in Xenopus embryos. Cell 1996, 86:391-399.

30. Kanter JE, Johansson F, LeBoeuf RC, Bornfeldt KE: Do glucose and lipids exert independent effects on atherosclerotic lesion initiation or progression to advanced plaques? Circ Res 2007, 100:769-781.

31. Renard CB, Kramer F, Johansson F, Lamharzi N, Tannock LR, von Herrath MG, Chait A, Bornfeldt KE: Diabetes and diabetes-associated lipid abnormalities have distinct effects on initiation and progression of atherosclerotic lesions. J Clin Invest 2004, 114:659-668.

32. Haidari M, Zhang W, Ganjehei L, Ali M, Chen Z: Inhibition of MLC phosphorylation restricts replication of influenza virus-a mechanism of action for anti-influenza agents. PLoS One 2011, 6:e21444.

33. Hirano K: Current topics in the regulatory mechanism underlying the $\mathrm{Ca} 2+$ sensitization of the contractile apparatus in vascular smooth muscle. J Pharmacol Sci 2007, 104:109-115.

34. Kimura $K$, Ito M, Amano M, Chihara K, Fukata $Y$, Nakafuku M, Yamamori $B$, Feng J, Nakano T, Okawa K, Iwamatsu A, Kaibuchi K: Regulation of myosin phosphatase by Rho and Rho-associated kinase (Rho-kinase). Science 1996, 273:245-248

35. Klemke RL, Cai S, Giannini AL, Gallagher PJ, de Lanerolle P, Cheresh DA: Regulation of cell motility by mitogen-activated protein kinase. J Cell Biol 1997, 137:481-492.

36. Lincoln TM: Myosin phosphatase regulatory pathways: different functions or redundant functions? Circ Res 2007, 100:10-12.

37. Nguyen DH, Catling AD, Webb DJ, Sankovic M, Walker LA, Somlyo AV, Weber MJ, Gonias SL: Myosin light chain kinase functions downstream of Ras/ERK to promote migration of urokinase-type plasminogen activator-stimulated cells in an integrin-selective manner. J Cell Biol 1999, 146:149-164.

38. Bruewer M, Hopkins AM, Hobert ME, Nusrat A, Madara JL: RhoA, Rac1, and Cdc42 exert distinct effects on epithelial barrier via selective structural and biochemical modulation of junctional proteins and F-actin. Am J Physiol Cell Physiol 2004, 287:C327-335.

39. Miyake Y, Inoue N, Nishimura K, Kinoshita N, Hosoya H, Yonemura S: Actomyosin tension is required for correct recruitment of adherens junction components and zonula occludens formation. Exp Cell Res 2006, 312:1637-1650.

40. Cain RJ, Vanhaesebroeck B, Ridley AJ: The PI3K p110alpha isoform regulates endothelial adherens junctions via Pyk2 and Rac1. J Cell Biol 2010, 188:863-876.

41. Lambeng N, Wallez Y, Rampon C, Cand F, Christe G, Gulino-Debrac D, Vilgrain I, Huber P: Vascular endothelial-cadherin tyrosine phosphorylation in angiogenic and quiescent adult tissues. Circ Res 2005, 96:384-391.

42. Raghunath PN, Tomaszewski JE, Brady ST, Caron RJ, Okada SS, Barnathan ES: Plasminogen activator system in human coronary atherosclerosis. Arterioscler Thromb Vasc Biol 1995, 15:1432-1443.
43. Reichel CA, Uhl B, Lerchenberger M, Puhr-Westerheide D, Rehberg M, Liebl J, Khandoga A, Schmalix W, Zahler S, Deindl E, Lorenzl S, Declerck PJ, Kanse S, Krombach F: Urokinase-type plasminogen activator promotes paracellular transmigration of neutrophils via Mac-1, but independently of urokinase-type plasminogen activator receptor. Circulation 2011, 124:1848-1859.

44. Esser S, Lampugnani MG, Corada M, Dejana E, Risau W: Vascular endothelial growth factor induces VE-cadherin tyrosine phosphorylation in endothelial cells. J Cell Sci 1998, 111:1853-1865.

45. Behzadian MA, Windsor LJ, Ghaly N, Liou G, Tsai NT, Caldwell RB: VEGF-induced paracellular permeability in cultured endothelial cells involves urokinase and its receptor. FASEB J 2003, 17:752-754.

46. Kanse SM, Benzakour O, Kanthou C, Kost C, Lijnen HR, Preissner KT: Induction of vascular SMC proliferation by urokinase indicates a novel mechanism of action in vasoproliferative disorders. Arterioscler Thromb Vasc Biol 1997, 17:2848-2854.

47. Aguirre Ghiso JA, Kovalski K, Ossowski L: Tumor dormancy induced by downregulation of urokinase receptor in human carcinoma involves integrin and MAPK signaling. J Cell Biol 1999, 147:89-104.

48. Tang H, Kerins DM, Hao Q, Inagami T, Vaughan DE: The urokinase-type plasminogen activator receptor mediates tyrosine phosphorylation of focal adhesion proteins and activation of mitogen-activated protein kinase in cultured endothelial cells. J Biol Chem 1998, 273:18268-18272.

49. Desbois-Mouthon C, Cadoret A, Blivet-Van Eggelpoel MJ, Bertrand F, Cherqui G, Perret C, Capeau J: Insulin and IGF-1 stimulate the beta-catenin pathway through two signalling cascades involving GSK-3beta inhibition and Ras activation. Oncogene 2001, 20:252-259.

doi:10.1186/1475-2840-13-105

Cite this article as: Haidari et al:: Disruption of endothelial adherens junctions by high glucose is mediated by protein kinase $C$ - $\beta$-dependent vascular endothelial cadherin tyrosine phosphorylation. Cardiovascular Diabetology 2014 13:105

\section{Submit your next manuscript to BioMed Central and take full advantage of:}

- Convenient online submission

- Thorough peer review

- No space constraints or color figure charges

- Immediate publication on acceptance

- Inclusion in PubMed, CAS, Scopus and Google Scholar

- Research which is freely available for redistribution 